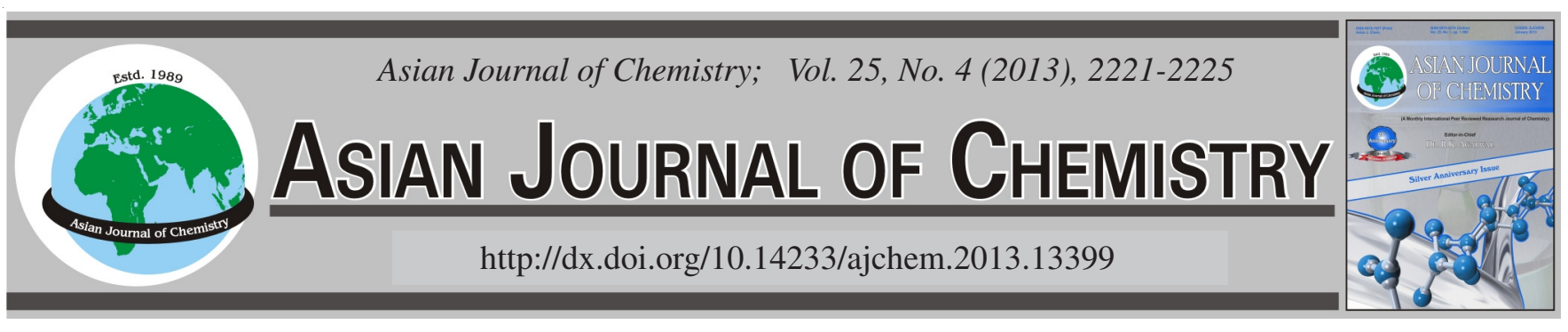

\title{
Electrical Conductance and Ion Pair Formation of S-Acetylthiocholine Halides in Methanol-Water Mixtures at $25^{\circ} \mathrm{C}$
}

\author{
Nasr H. El-Hammamy ${ }^{1}$, Howaida M. El-Kashlan ${ }^{2, *}$ and Heba M. Moharem ${ }^{1}$
}

${ }^{1}$ Department of Chemistry, Faculty of Science, Alexandria University, Alexandria, Egypt

${ }^{2}$ Department of Physics and Chemistry, Faculty of Education, Alexandria University, Alexandria, Egypt

*Corresponding author: E-mail: helkashlan@ hotmail.com

(Received: 6 January 2012;

Accepted: 17 October 2012)

AJC-12315

Conductance of S-acetylthiocholine halides is measured at $25^{\circ} \mathrm{C}$ in methanol-water mixtures $(35.1<\mathrm{D}<73.7)$. The conductance parameters derived from the Fuoss-Onsager conductance theory indicate that the solvation of halides decreases with the decrease of the dielectric constants until a certain minimum and then increases again. The plot of $\log \mathrm{K}_{\mathrm{A}}$ versus 1/D is found to be non-linear indicating that the equation of association cannot be applied. The association constant is analyzed using the solvent separated-ion pair model.

Key Words: Electrical conductance, Ion pair formation.

\section{INTRODUCTION}

Ion-pair formation of S-acetylthiocholine halides in methanol solution was studied ${ }^{1}$. The conductometric measurements of these salts in methanol-water mixtures at $25^{\circ} \mathrm{C}$ are recorded and then analyzed in an attempt to illustrate the electrolyte-solvent interaction, using the Fuoss-Onsager equation ${ }^{2}$. The relation between $\mathrm{K}_{\mathrm{A}}$ and size of anions in the above mentioned medium is discussed.

\section{EXPERIMENTAL}

Purification of S-acetylthiocholine halides are reported ${ }^{1}$. Methanol (BDH) was purified as reported ${ }^{1}$. Its specific conductance $\chi^{\mathrm{o}}$ amounted to $\left(2.72-7.08 \times 10^{-7}\right) \mathrm{ohm}^{-1} \mathrm{~cm}^{-1}$.

Conductivity water was prepared as reported ${ }^{3}$. Its specific conductance $\chi^{\mathrm{o}}$ amounts to $\left(5-7 \times 10^{-6}\right) \mathrm{ohm}^{-1} \mathrm{~cm}^{-1}$.

Properties of solvent mixtures: Densities (d) of the mixtures were determined using a $20 \mathrm{~mL}$ pyknometer at $25 \pm$ $0.02{ }^{\circ} \mathrm{C}$. Viscosities $(\eta)$ were measured using modified Ubeloehde suspended level viscometer with flow time at 25 ${ }^{\circ} \mathrm{C}$ of $172.4 \mathrm{~s}$ for conductivity water. Dielectric constants (D) were obtained by interpolation from a large scale plot of data ${ }^{4}$. In the same way viscosities and densities of experimental solvent mixtures used were interpolated from large scale plots of their data. All solutions were weighted on microbalance with read $\pm 0.1 \mathrm{mg}$. Dilution was carried out successively into the cell by siphoning the solvent by means of a weighing pipette.
Conductivity bridge was model Crison $\mathrm{Cl}$ p 31 and the cell with bright platinum electrodes was used. The cell constant was $0.1 \mathrm{~cm}^{-1}$ for dilute solution.

\section{RESULTS AND DISCUSSION}

Conductance data for $\mathrm{S}$-acetylthiocholine halides in methanol-water mixtures at $25^{\circ} \mathrm{C}$ are obtained and represented in Fig. 1, where the equivalent conductance $\Lambda\left(\mathrm{ohm}^{-1}\right.$ equiv $^{-1}$ $\left.\mathrm{cm}^{2}\right)$ is given at several concentrations $\mathrm{C}$ is equiv/liter.

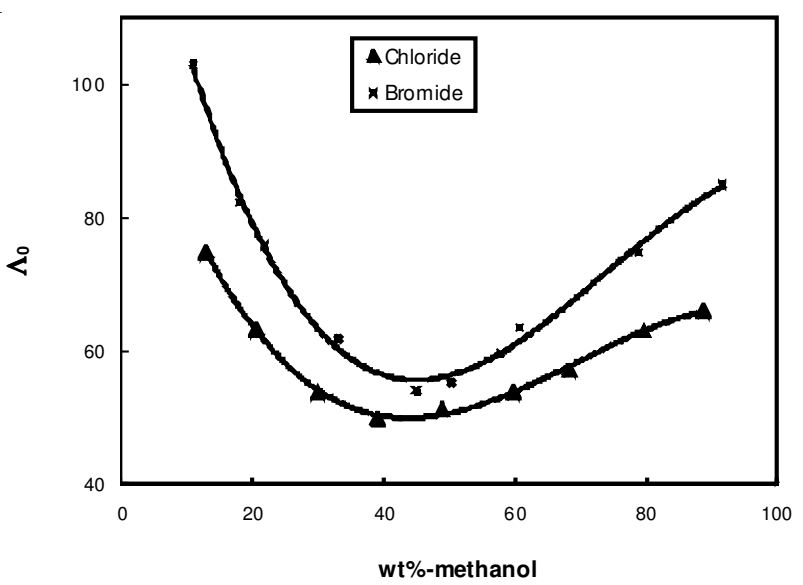

Fig. 1. Variation of $\Lambda$. of S-acetylthiocholine salts with the composition of solvent mixtures

The data analyzed on an IBM-PC computer using the Fuoss-Onsager equation. In all computations the accuracies 
required for the absolute values deviations are: \pm 0.02 for $\Lambda$, 5 for $J<200, \pm 10$ for $J=200 \rightarrow 1000$ and \pm 15 for $J>1000$. The results are depicted in Table-1.

It can be readily seen from Table- 1 and Fig. 1 that $\Lambda$. for S-acetylthiocholine halides exhibit minima at 43 wt $\%$ methanol.

The occurrence of a minimum in the value of $\Lambda_{0}$ is an unexpected behaviour. Since on decreasing the dielectric constant, the ionic mobilities are hindered and the chance for ion-pair formation is more prevailing, so $\Lambda$. should decrease with decrease of the dielectric constant. Figs. 2 and 3 show that $\mathrm{a}^{\mathrm{o}}, J$ and $\mathrm{K}_{\mathrm{A}}$ pass through minimum values at certain dielectric constants.

The initial decreases in $\mathrm{a}^{\circ}$ for s-acetylthiocholine halides can be explained on the basis that the strength of hydrogen bonds between ions and water are so high to be affected by adding small amounts of methanol. On increasing methanol content depolymerisation occurs and an increase of $\mathrm{a}^{\mathrm{o}}$ values is observed.

The minimum in $\log \mathrm{K}_{\mathrm{A}}$ versus 1/D plot may be explained on the basis that water is a highly associated solvent due to hydrogen bonds forming polymeric aggregates ${ }^{5}$. It is possible that pure water can stabilize the ion-pairs formed as a result of the molecular chains created by hydrogen bonding. On addition of methanol depolymerization occurs and less associated forms are produced, since it was seen from density and viscosity studies ${ }^{6}$ that methanol-water is a strong hydrogen bonded system. On further increasing the methanol content the $\mathrm{K}_{\mathrm{A}}$ values tend to increase regularly. In this region, it is assumed that over a certain methanol concentration, the water structure could affect the association process of the ions and would undergo less marked variation. The trend of $\mathrm{a}^{\circ}$ shows that, on addition of methanol to water $\mathrm{a}^{\circ}$ decreases (solvation decreases) till a minimum value and then increases for methanolrich solution? ${ }^{7}$.

From the above picture of variation of both $\mathrm{a}^{\mathrm{o}}$ and $\mathrm{K}_{\mathrm{A}}$ with dielectric constant, one can conclude that the sphere of
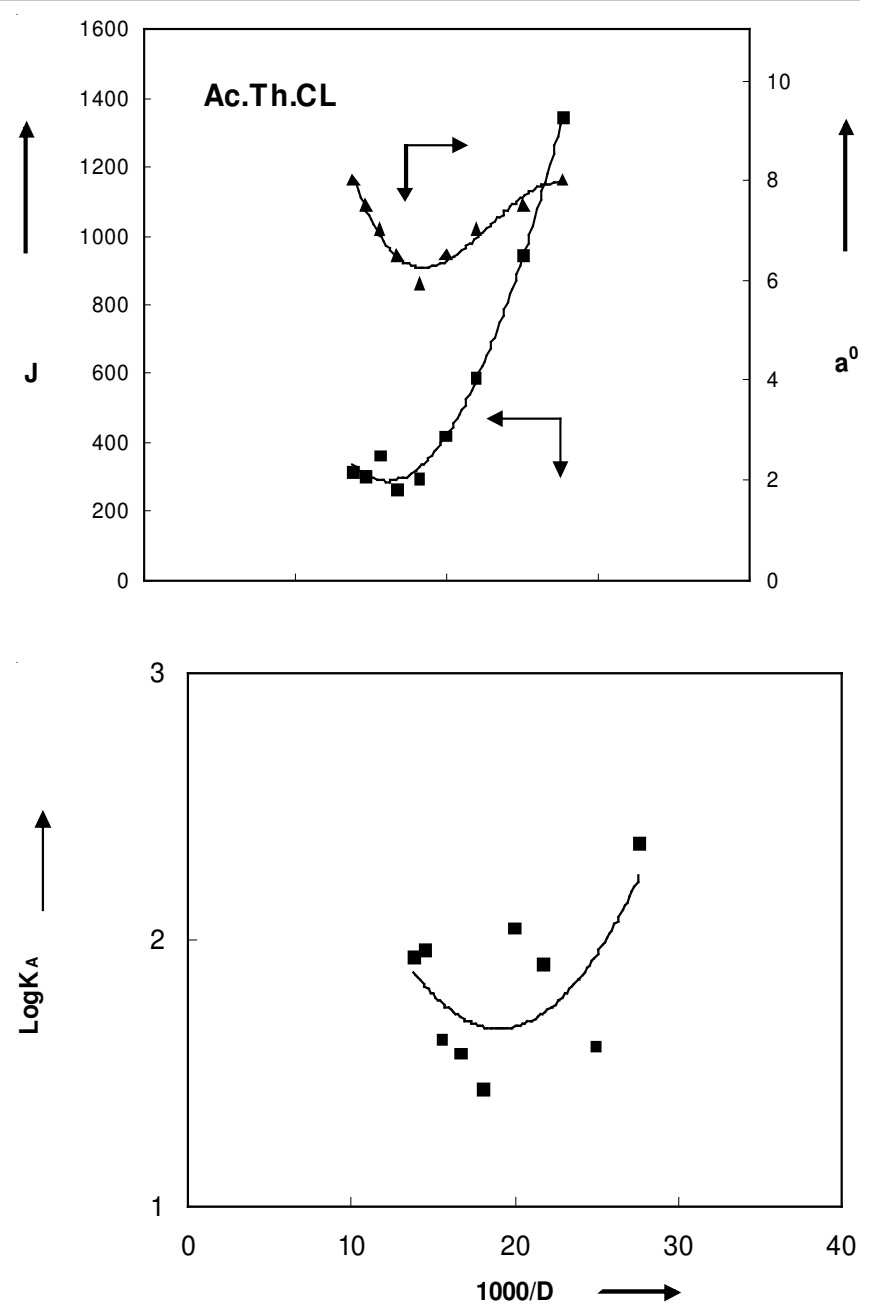

Fig. 2. Variation of $J, \mathrm{a}^{\mathrm{o}}$ and $\log \mathrm{K}_{\mathrm{A}}$ with dielectric constant of methanolwater mixtures

continuum model cannot be applied to these systems. Further evidence in support of this conclusion can be obtained by using the expression ${ }^{8}$.

TABLE-1

CHARATERISTIC PARAMETERS FOR S-ACETYLTHIOCHOLINE SALTS IN METHANOL-WATER MIXTURES AT $25^{\circ} \mathrm{C}$

\begin{tabular}{|c|c|c|c|c|c|c|c|c|}
\hline $\mathrm{Wt}(\%)$ & $\mathrm{D}$ & $1000 / \mathrm{D}$ & $\Lambda_{0}$ & $J$ & $a^{o}$ & $\mathrm{~K}_{\mathrm{A}}$ & $\log \mathrm{K}_{\mathrm{A}}$ & $\sigma_{\mathrm{A}}$ \\
\hline \multicolumn{9}{|c|}{ S-Acetylthiocholine chloride } \\
\hline 12.96 & 72.5 & 13.7931 & 74.699 & 314.45 & 7.988 & 85.604 & 1.9325 & 0.021 \\
\hline 20.61 & 68.8 & 14.5349 & 63.222 & 300.48 & 7.513 & 90.689 & 1.9576 & 0.011 \\
\hline 29.99 & 64.4 & 15.5280 & 53.930 & 363.15 & 7.000 & 42.386 & 1.6272 & 0.007 \\
\hline 38.97 & 60.0 & 16.6667 & 49.755 & 263.13 & 6.488 & 37.566 & 1.5748 & 0.017 \\
\hline 49.01 & 55.3 & 18.0832 & 51.297 & 296.24 & 5.938 & 27.245 & 1.4353 & 0.160 \\
\hline 59.64 & 50.2 & 19.9203 & 53.962 & 419.07 & 6.500 & 110.87 & 2.0448 & 0.014 \\
\hline 68.26 & 45.8 & 21.8341 & 57.238 & 585.27 & 7.000 & 80.170 & 1.9040 & 0.015 \\
\hline 79.77 & 40.0 & 25.0000 & 63.078 & 943.10 & 7.500 & 39.591 & 1.5976 & 0.008 \\
\hline 88.68 & 36.2 & 27.6243 & 66.030 & 1344.0 & 8.000 & 108.75 & 2.3643 & 0.014 \\
\hline \multicolumn{9}{|c|}{ S-Acetylthiocholine bromide } \\
\hline 10.87 & 73.7 & 13.5685 & 103.04 & 367.18 & 7.500 & 113.09 & 2.0524 & 0.035 \\
\hline 17.87 & 70.2 & 14.2450 & 82.318 & 316.83 & 7.125 & 113.44 & 2.0548 & 0.070 \\
\hline 21.70 & 68.3 & 14.6413 & 75.884 & 289.60 & 6.600 & 193.20 & 2.2860 & 0.020 \\
\hline 33.04 & 62.9 & 15.8983 & 61.952 & 264.01 & 6.025 & 76.019 & 1.8809 & 0.023 \\
\hline 50.31 & 54.8 & 18.2482 & 55.311 & 297.51 & 5.013 & 88.152 & 1.9451 & 0.016 \\
\hline 57.80 & 51.1 & 19.5695 & 59.721 & 375.83 & 5.494 & 73.837 & 1.8683 & 0.011 \\
\hline 60.75 & 49.6 & 20.1613 & 63.485 & 426.52 & 5.500 & 43.691 & 1.6404 & 0.014 \\
\hline 78.94 & 40.7 & 24.5700 & 74.904 & 915.26 & 6.338 & 89.401 & 1.9513 & 0.158 \\
\hline 91.76 & 35.1 & 28.4900 & 84.974 & 1159.1 & 7.013 & 55.376 & 1.7433 & 0.013 \\
\hline
\end{tabular}




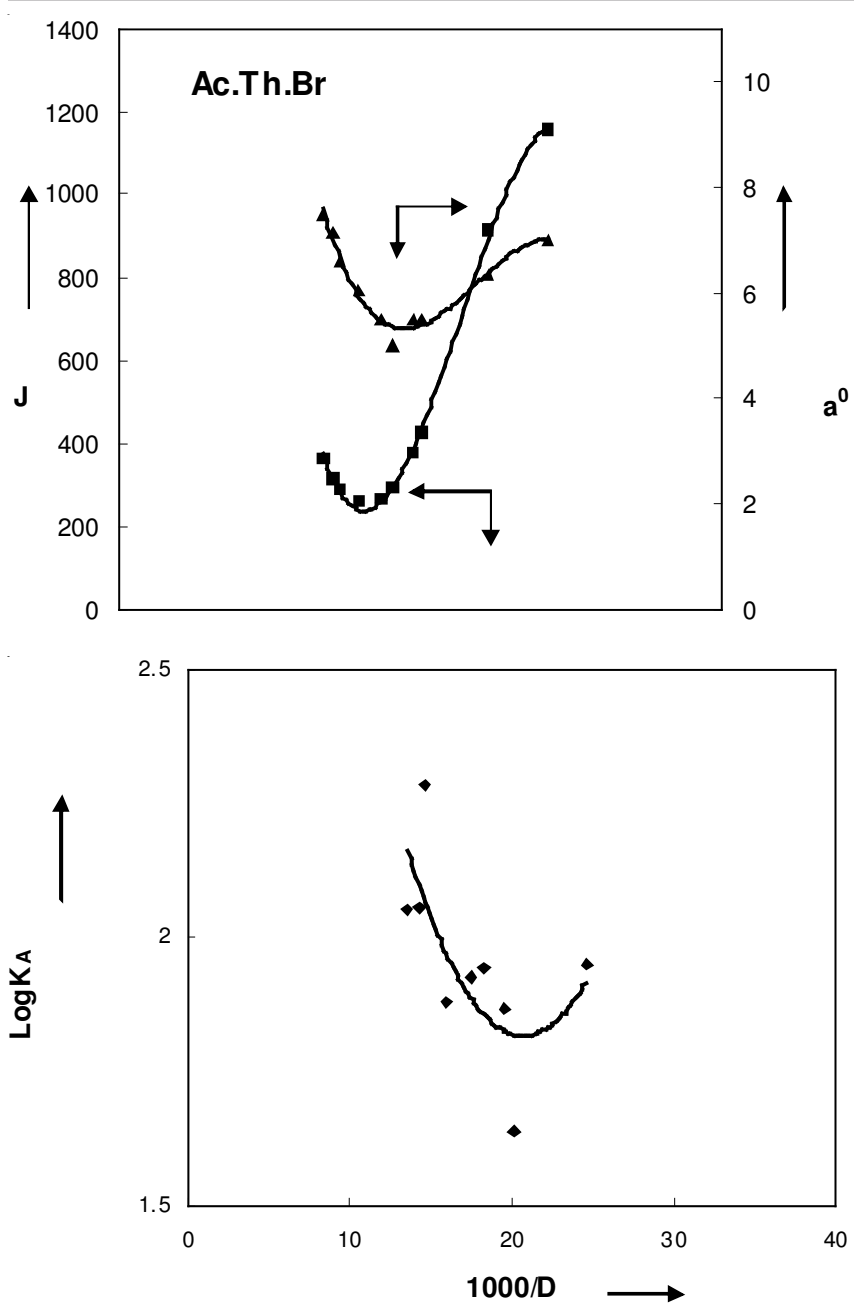

Fig. 3. Variation of $J, \mathrm{a}^{\mathrm{o}}$ and $\log \mathrm{K}_{\mathrm{A}}$ with dielectric constant of methanolwater mixtures

$$
\ln \mathrm{K}_{\mathrm{A}}=\ln \left(\frac{4 \pi \mathrm{Na}^{03}}{3000}\right)+\frac{\mathrm{e}^{2}}{\mathrm{a}^{\mathrm{o}} \mathrm{DkT}}+\mathrm{U}
$$

where $\mathrm{U}=\frac{\Delta \mathrm{S}}{\mathrm{k}}-\frac{\mathrm{Es}}{\mathrm{kT}}$.

The factor Es/kT was introduced by Gilkerson ${ }^{9}$ to account for the energy of ion-dipole interaction, which should be different from that when ion-pairs are considered. The entropy term $\Delta \mathrm{S} / \mathrm{k}$ was included ${ }^{8}$ to account for the change of entropy due to different arrangements of solvent molecules around free ions and ion-pairs.

The last column in Table-2 shows that $\mathrm{U}$ term decreased slightly as methanol wt \% increases. This may be due to the fact that the entropy/Boltzman ratio $\Delta \mathrm{S} / \mathrm{k}$ decreases as the dielectric constant of medium decreases. This means that the ion-dipole interaction term increases as a result of modification of structure of the mixed solvent and interaction between solute and solvent.

Finally, the solvent separated ion pairs model $^{10}$ is applied as follows:

$(\mathrm{S} \text {-Acetylthiocholine })^{+}+\mathrm{X}^{-}(\text {solvent })_{\mathrm{n}}$<smiles>[123I]C[Al]1C[Al]1</smiles>

$(\text { S-Acetylthiocholine })^{+}(\text {solvent })_{\mathrm{n}} \mathrm{X}^{-}$ (Case I) Solvated form

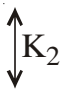

(S-Acetylthiocholine) X (solvent) $)_{\mathrm{n}-1}$ (Case II) Desolvated form

The association constant is given by expression:

$$
\begin{aligned}
\mathrm{K}_{\mathrm{A}}=\mathrm{K} \Sigma & =\frac{\left[\mathrm{C}_{(\text {Ion-pairs })}\right]}{\left[\mathrm{C}_{(\text {s-acetylthiocholine })^{+}}\right]\left[\mathrm{C}_{\mathrm{X} \text {-(solvent) })_{\mathrm{n}}}\right]} \\
& =\mathrm{K}_{1}\left(1+\mathrm{K}_{2}\right)
\end{aligned}
$$

where $\mathrm{K} \Sigma=\mathrm{K}_{\mathrm{A}}$ is obtained from conductance measurements $\mathrm{K}_{1}=4 \pi \mathrm{Na}^{03} \mathrm{e}^{\mathrm{b}} / 3000$ then $\mathrm{K}_{2}$ can be calculated $\mathrm{b}=\mathrm{e}^{2} / \mathrm{a}^{\mathrm{o}} \mathrm{DkT}$.

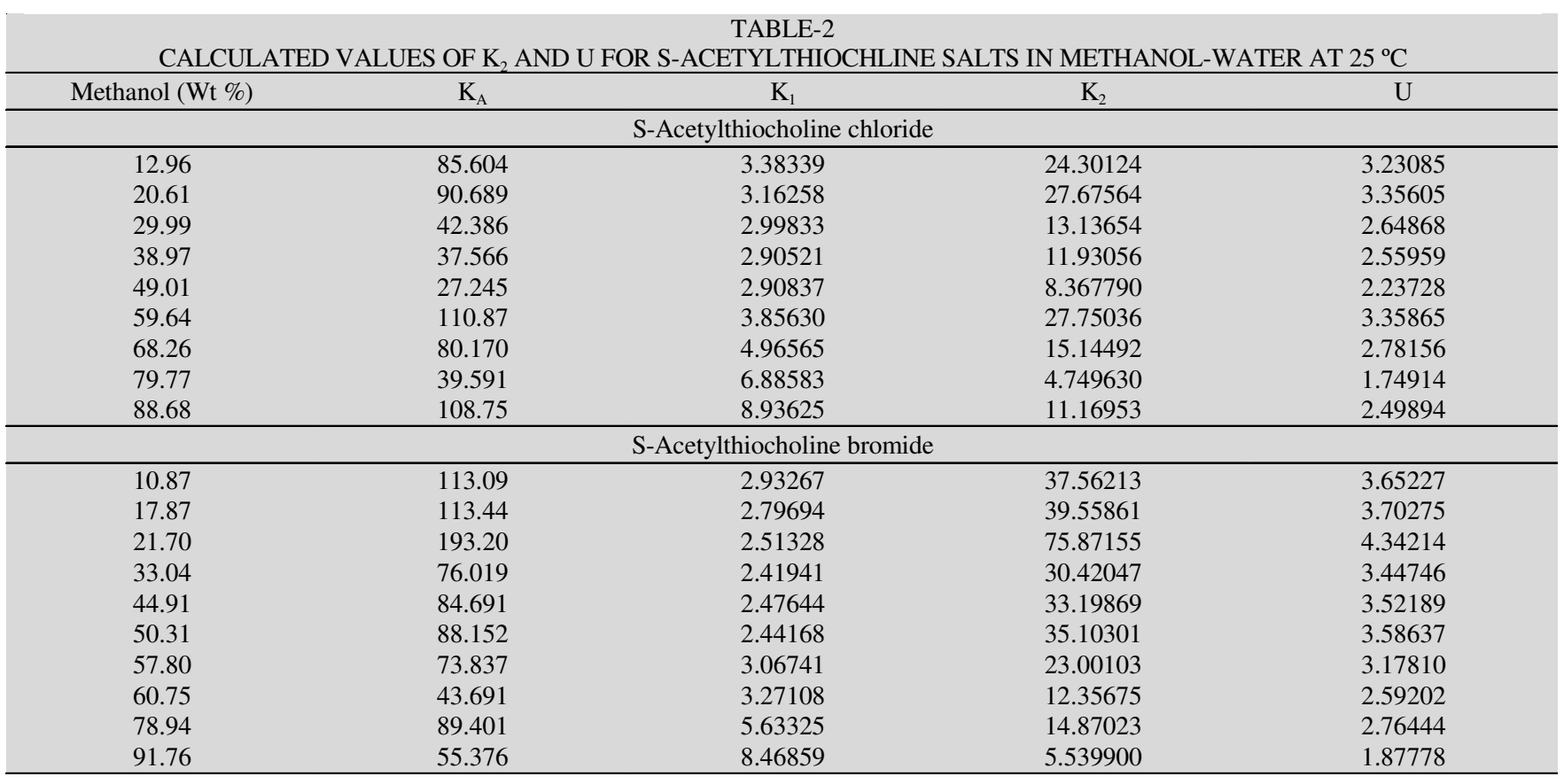


From Table- 2 it is evident that $\mathrm{K}_{2}$ decrease as the dielectric constant decrease. This means that as the dielectric constant decrease as the ion-pair prefers the more solvated form (Case I), i.e., the disturbance due to orientation of solvent molecules around the ion and ion pair decreases by decreasing dielectric constant. This is in good agreement with result of $U$ and $\mathrm{K}_{\mathrm{A}}$.

Fig. 4 shows that the Walden product $\Lambda_{\circ} \eta_{\circ}$, a function of solvent composition, for $\mathrm{S}$-acetylthicholine halides in methanolwater mixtures at $25^{\circ} \mathrm{C}$ varies in the usual manner, i.e., it decreases with decreasing dielectric constant. This is in agreement with general findings on several small size (uni-univalent $)^{11,12}$ and (bi-bivalent) ${ }^{13}$ systems and can be attributed to ion-solvent relaxation $\operatorname{drag}^{14,15}$.

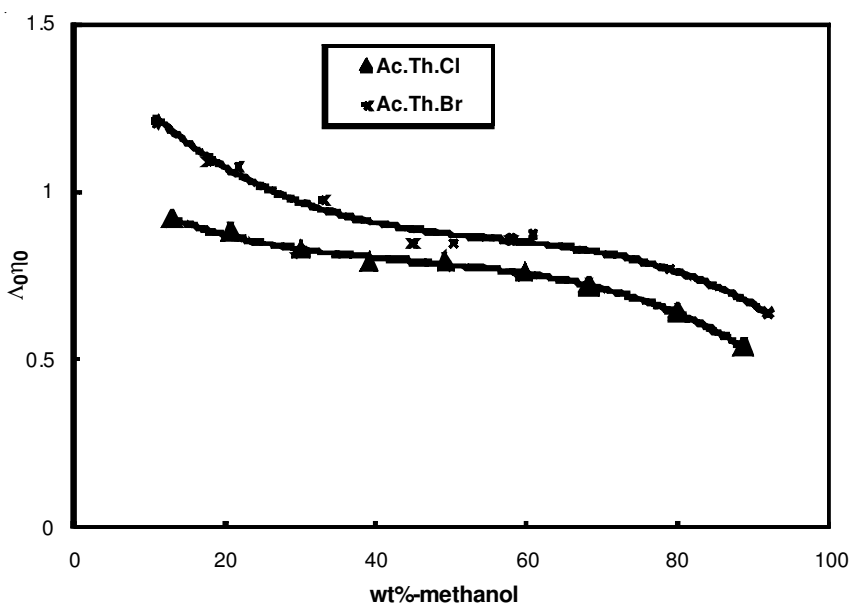

Fig. 4. Variation of Walden product with composition of solvent mixtures

The electrostatic radii $\mathrm{R}^{+}$and $\mathrm{R}^{-}$can be determined by using the Stokes equation in the following form: $\mathrm{R} \pm=0.8194$ $\times 10^{-8} / \lambda_{\bullet} \eta_{\text {。 }}$. It is clear that application of Stokes equation needs the determination of the true values of ionic conductance. According to the Fuoss assumption ${ }^{16}$ that the transport number is independent of the solvent composition, the ionic equivalent conductance for cations and anions in methanol-water mixtures are calculated and introduced in the Stokes equation. The results are contained in Table- 3 .

It can be readily seen from Table- 4 that the values of $\mathrm{R}^{+}$ and $\mathrm{R}^{-}$increase on decreasing the dielectric constant. This can be explained on the basis that the addition of water to an alcoholic electrolyte solution diminishes the ionic radii ${ }^{17}$. On comparing the summation of electrostatic radii $\left(\mathrm{R}^{+}+\mathrm{R}^{-}\right)$with the closest distance of approach $\mathrm{a}^{\mathbf{o}}$ which was previously derived using Fuoss-Onsager equation, one can observe that $\mathrm{a}^{\mathrm{o}}$ is always greater except in case of rich methanol content. The behaviour can be explained on the basis of Nightingale ${ }^{18}$ conclusions. The summation $\left(\mathrm{R}^{+}+\mathrm{R}^{-}\right)$increases with decreasing the dielectric constant of the medium which may be due to cosolvent structure ${ }^{19}$.

\begin{tabular}{cccc}
\multicolumn{5}{c}{ TABLE-3 } \\
\multicolumn{5}{c}{ IONIC EQUIVALENT CONDUCTANCE FOR } \\
\multicolumn{4}{c}{ S-ACETYLTHOCHOLINE SALTS IN METHANOL- } \\
WATER MIXTURES AT 25 ${ }^{\circ} \mathrm{C}$ \\
\hline Methanol (wt \%) & $\Lambda^{\circ}$ & $\lambda^{-}$ \\
\hline \multicolumn{4}{c}{ S-Acetylthiocholine chloride } \\
\hline 12.96 & 74.699 & 61.13142 & $\lambda^{+}$ \\
20.61 & 63.222 & 51.73899 & 13.56758 \\
29.99 & 53.930 & 44.13469 & 9.795310 \\
38.97 & 49.755 & 40.71800 & 9.037600 \\
49.01 & 51.297 & 41.97993 & 9.317070 \\
59.64 & 53.962 & 44.16088 & 9.801120 \\
68.26 & 57.238 & 46.84186 & 10.39614 \\
79.77 & 63.078 & 51.62114 & 11.45686 \\
88.68 & 66.030 & 54.03697 & 11.99303 \\
\hline \multicolumn{4}{c}{ S-Acetylthiocholine bromide } \\
\hline 10.87 & 103.04 & 84.28363 \\
17.87 & 82.318 & 67.33365 & 18.75637 \\
21.70 & 75.884 & 62.07084 & 14.98435 \\
33.04 & 61.952 & 50.67487 & 13.81316 \\
44.91 & 53.987 & 44.15975 & 9.827250 \\
50.31 & 55.311 & 45.24274 & 10.06826 \\
57.80 & 59.721 & 48.84999 & 10.87101 \\
60.75 & 63.485 & 51.92883 & 11.55617 \\
78.94 & 74.904 & 61.26922 & 13.63478 \\
91.76 & 84.974 & 69.50618 & 15.46782 \\
\hline \multicolumn{4}{c}{}
\end{tabular}

TABLE-4

CALCULATION OF RADII OF THE IONS FOR S-ACETYLTHIOCHOLINE SALTS IN METHANOL-WATER MIXTURES AT $25^{\circ} \mathrm{C}$

\begin{tabular}{|c|c|c|c|c|c|c|c|}
\hline Methanol (Wt \%) & $\Lambda \cdot \eta_{\circ}$ & $\lambda_{0}-\eta_{0}$ & $\lambda_{0}^{+} \eta_{\circ}$ & $\mathrm{R}^{-}$ & $\mathrm{R}^{+}$ & $\mathrm{R}^{+}+\mathrm{R}^{-}$ & $a^{o}$ \\
\hline \multicolumn{8}{|c|}{ S-Acetylthiocholine chloride } \\
\hline 12.96 & 0.91611 & 0.74972 & 0.16639 & 1.093 & 4.925 & 6.018 & 7.988 \\
\hline 20.61 & 0.87910 & 0.71943 & 0.15967 & 1.139 & 5.132 & 6.271 & 7.513 \\
\hline 29.99 & 0.83101 & 0.68007 & 0.15094 & 1.205 & 5.429 & 6.634 & 7.000 \\
\hline 38.97 & 0.79071 & 0.64709 & 0.14362 & 1.266 & 5.705 & 6.971 & 6.488 \\
\hline 49.01 & 0.79454 & 0.65023 & 0.14431 & 1.260 & 5.678 & 6.938 & 5.938 \\
\hline 59.64 & 0.75887 & 0.62103 & 0.13783 & 1.319 & 5.945 & 7.264 & 6.500 \\
\hline 68.26 & 0.71885 & 0.58829 & 0.13257 & 1.393 & 6.276 & 7.669 & 7.000 \\
\hline 79.77 & 0.64125 & 0.52478 & 0.11647 & 1.561 & 7.035 & 8.596 & 7.500 \\
\hline 88.68 & 0.53808 & 0.44034 & 0.09773 & 1.860 & 8.384 & 10.244 & 8.000 \\
\hline \multicolumn{8}{|c|}{ S-Acetylthiocholine bromide } \\
\hline 10.87 & 1.21072 & 0.99033 & 0.22039 & 0.827 & 3.718 & 4.545 & 7.500 \\
\hline 17.87 & 1.09129 & 0.89352 & 0.19884 & 0.917 & 4.121 & 5.038 & 7.125 \\
\hline 21.70 & 1.07535 & 0.87812 & 0.19541 & 0.933 & 4.193 & 5.126 & 6.600 \\
\hline 33.04 & 0.97457 & 0.79712 & 0.17739 & 1.028 & 4.619 & 5.647 & 6.025 \\
\hline 50.31 & 0.84930 & 0.69470 & 0.15460 & 1.180 & 5.300 & 6.480 & 5.012 \\
\hline 57.80 & 0.85933 & 0.70290 & 0.15642 & 1.166 & 5.238 & 6.404 & 5.494 \\
\hline 60.75 & 0.87400 & 0.71490 & 0.15909 & 1.146 & 5.151 & 6.297 & 5.500 \\
\hline 78.94 & 0.77353 & 0.63273 & 0.14081 & 1.295 & 5.819 & 7.114 & 6.338 \\
\hline 91.76 & 0.63510 & 0.51949 & 0.11561 & 1.577 & 7.088 & 8.665 & 7.013 \\
\hline
\end{tabular}




\section{REFERENCES}

1. N.H. El-Hammamy, A.I. Kawana, S.A. El-Shazly and H.M. Moharem, J. Alex. Pharm. Sci., 24, 97 (2010).

2. R.M. Fuoss and L. Onsager, J. Phys. Chem., 61, 668 (1957); R.M. Fuoss and L. Onsager, J. Am. Chem. Soc., 81, 2659 (1959).

3. N.H. El-Hammamy, A.I. Kawana, M.F. Amira and N.S. El-Sisy, Int. J. Pharm. Biol. Sci., 1, 1 (2010).

4. A.R. Gupta, J. Phys. Chem., 83, 23 (1979).

5. M. Ageno, Proc. Nat. Acad. Sci., 57, 856 (1967).

6. N.H. El-Hammamy, H. Sadek, A.M. Hafez and G.A. Ibrahim, J. Alex. Pharm. Sci., 23, 20 (2009).

7. N.H. El-Hammamy, S.A. Shazly, A.I. Kawana and F.M. Abd El-Halim, J. Chem. Soc. Pak., 13, 236 (1991).
8. Accasina, A.D. Aprano and R. Triolo, J. Phys. Chem., 71, 3474 (1967).

9. W.R. Gilkerson, J. Chem. Phys., 25, 1199 (1956).

10. D.F. Evans and P. Gardam, J. Phys. Chem., 73, 158 (1969).

11. J.E. Lind and R.M. Fuoss, J. Phys. Chem., 65, 1001 (1961).

12. R.W. Kunze and R.M. Fuoss, J. Phys. Chem., 67, 911 (1963).

13. G. Atkinsen and S. Petrucci, J. Am. Chem. Soc., 86, 7 (1964).

14. R.M. Fuoss, Proc. Nat. Acad. Sci. USA, 45, 807 (1959).

15. R. Zwanzig, J. Chem. Phys., 38, 1603 (1963).

16. H. Sadek and R.M. Fuoss, J. Am. Chem. Sci., 81, 4507 (1959).

17. J.T. Denison and J.B. Ramsay, J. Am. Chem. Soc., 77, 2615 (1955).

18. E.R. Nightingale, J. Phys. Chem., 62, 1381 (1959).

19. N.H. El-Hammamy, A.A. Hasanien, H.A. Mahmoud and F.M. Abd ElHlem, J. Chem. Soc. Pak., 8, 125 (1986). 